\title{
Hemangioma fusocelular en las fosas nasales y los senos etmoidales en un lactante de 4 meses de edad
}

Spindle cell hemangioma of nasal passage and ethmoidal sinus in a 4-month old infant

\author{
Dra. Tugba Tastemel Ozturk, Prof. Ahmet E. Suslub, Dr. Altan Kavuncuogluc, Dra. Ekim Gumelerd, \\ Prof. Asoc. Kemal Kosemehmetogluc y Dr. Bilgehan Yalcin ${ }^{e}$
}

\section{RESUMEN}

El hemangioma fusocelular es una neoplasia vascular benigna infrecuente. Afecta la dermis y la hipodermis de la parte distal de las extremidades; la afectación de la cabeza y el cuello es muy poco frecuente y nunca se informó compromiso de los senos paranasales. Este es el caso de un lactante de 4 meses con obstrucción nasal desde las 2 semanas debido a un tumor en los senos etmoidales que obstruía las fosas nasales. Se diagnosticó hemangioma fusocelular y se extirpó parcialmente el tumor. A los seis meses de seguimiento, se observó una regresión mínima con lesiones residuales. A los 30 meses, se observó que el tumor residual había desaparecido. El hemangioma fusocelular es infrecuente en cabeza y cuello y, a veces, la presentación no es indicativa del diagnóstico. El examen histopatológico ayuda con el diagnóstico diferencial y el tratamiento. La sensibilización sobre el hemangioma fusocelular podría aumentar los casos informados.

Palabras clave: pediatría, neoplasias de cabeza y cuello, senos paranasales, hemangioma fusocelular.

http: / / dx.doi.org/ 10.5546/ aap.2021.e36

Texto completo en inglés:

http: / / dx.doi.org/10.5546/ aap.2021.eng.e36

Cómo citar: Tastemel Ozturk T, Suslu AE, Kavuncuoglu A, Gumeler E, et al. Hemangioma fusocelular en las fosas nasales y los senos etmoidales en unlactante de 4 meses deedad. Arch Argent Pediatr 2021;119(1):e36-e40.

a. Departamento de Pediatría.

b. Departamento de Otorrinolaringología.

c. Departamento de Patología.

d. Departamento de Radiología.

e. División de Oncología Pediátrica, Departamento de Pediatría. Facultad de Medicina de Hacettepe Üniversitesi, Ankara, Turquía.

Correspondencia:

Dra. Tugba Tastemel Ozturk: t_tastemel@hotmail.com

Financiamiento: Ninguno.

Conflicto de intereses: Ninguno que declarar.

Recibido: 26-2-2020

Aceptado: 28-8-2020

\section{INTRODUCCIÓN}

El hemangioma fusocelular es una lesión vascular infrecuente descrita en 1986 por Weiss y Enzinger como hemangioendotelioma fusocelular similar al hemangioma cavernoso y sarcoma de Kaposi. ${ }^{1}$ Esta lesión se definió inicialmente como angiosarcoma de evolución lenta, pero debido a la ausencia de metástasis y al excelente pronóstico, se consideró una neoplasia vascular benigna, a pesar del elevado índice de recidivas locales; en 1996, se lo denominó hemangioma fusocelular. ${ }^{1,2}$ No se observa una diferencia en la prevalencia del hemangioma fusocelular entre hombres y mujeres, y puede producirse a cualquier edad. Afecta principalmente la dermis y la hipodermis de la parte distal de las extremidades. ${ }^{2} \mathrm{La}$ afectación de la cabeza y el cuello es muy poco frecuente. Hasta donde sabemos, se informaron 11 casos de hemangioma fusocelular en la región de cabeza y cuello hasta el momento, y nunca antes se había informado compromiso de los senos paranasales. ${ }^{3}$

En este artículo, presentamos el caso de un lactante de 4 meses de edad con obstrucción nasal causada por un hemangioma fusocelular en los senos etmoidales que obstruía las fosas nasales.

\section{A PROPÓSITO DE UN CASO}

Se ingresó al consultorio de otorrinolaringología a un lactante de sexo masculino de 4 meses de edad con obstrucción nasal. Según sus padres, tenía una inflamación leve en el párpado izquierdo y obstrucción nasal desde las 2 semanas de vida. Habían notado un bulto en la nariz a los 2 meses de edad. Se derivó al paciente a otro hospital, donde se lo sometió a una extirpación quirúrgica de la mayor parte del tumor, que obstruía la fosa nasal izquierda.

No se dispuso de la información sobre el examen histopatológico inicial de los tejidos extirpados. Debido a la naturaleza prominentemente vascular de la lesión, en el primer hospital se había iniciado propranolol por 
vía oral. El paciente ingresó a nuestro hospital por presentar nuevamente obstrucción nasal dos meses después de la cirugía. Fue evaluado por el Departamento de Otorrinolaringología y se hizo una biopsia por incisión del tumor de la fosa nasal izquierda. En el examen histopatológico, se observó un tumor fusocelular con espacios vasculares sólidos tipo hendidura debajo del epitelio respiratorio (Figura 1A). Al observarlo bajo un gran aumento, se notó que el tumor tenía células endoteliales epitelioides sin atipia citológica y que contenía vacuolas intracitoplasmáticas. Se observó extravasación eritrocitaria (Figura 1B). El tumor estaba acompañado de áreas papilares hialinizadas revestidas de una única capa de células endoteliales que coincidía con hiperplasia endotelial papilar (Figura 1C). En el examen inmunohistoquímico, se observó que las células tumorales eran positivas para CD31, lo que denotó su origen vascular (Figura 1D). El tumor fue negativo para HHV-8, D2-40, GLUT1 y desmina, lo que sirvió para diferenciarlo, respectivamente, del sarcoma de Kaposi, del hemangioendotelioma kaposiforme, del hemangioma infantil y del rabdomiosarcoma. Con base en estos hallazgos, al paciente se le diagnosticó hemangioma fusocelular e hiperplasia endotelial papilar.

En la resonancia magnética (RM), se observó un tumor lobulado en el seno etmoidal izquierdo, que se extendía hacia abajo, hacia el meato nasal medio y superior, y hacia arriba, hacia el seno frontal izquierdo a través de los senos frontoetmoidales. En el área extracónica orbitaria interior y superior, se observaron infiltraciones a través de la lámina papirácea y la pared inferior del seno frontal. Se encontró un festoneado en la pared superior del seno frontal. Las señales del tumor fueron hiperintensas en las imágenes ponderadas en $\mathrm{T} 2$, pero hipointensas en las imágenes ponderadas en T1; el tumor mostró un claro realce, aunque heterogéneo, después de la administración de un medio de contraste de gadolinio en las imágenes ponderadas en T1 (Figura 2). Se observaron vacíos de flujo vascular en las imágenes ponderadas en T2 y en aquellas
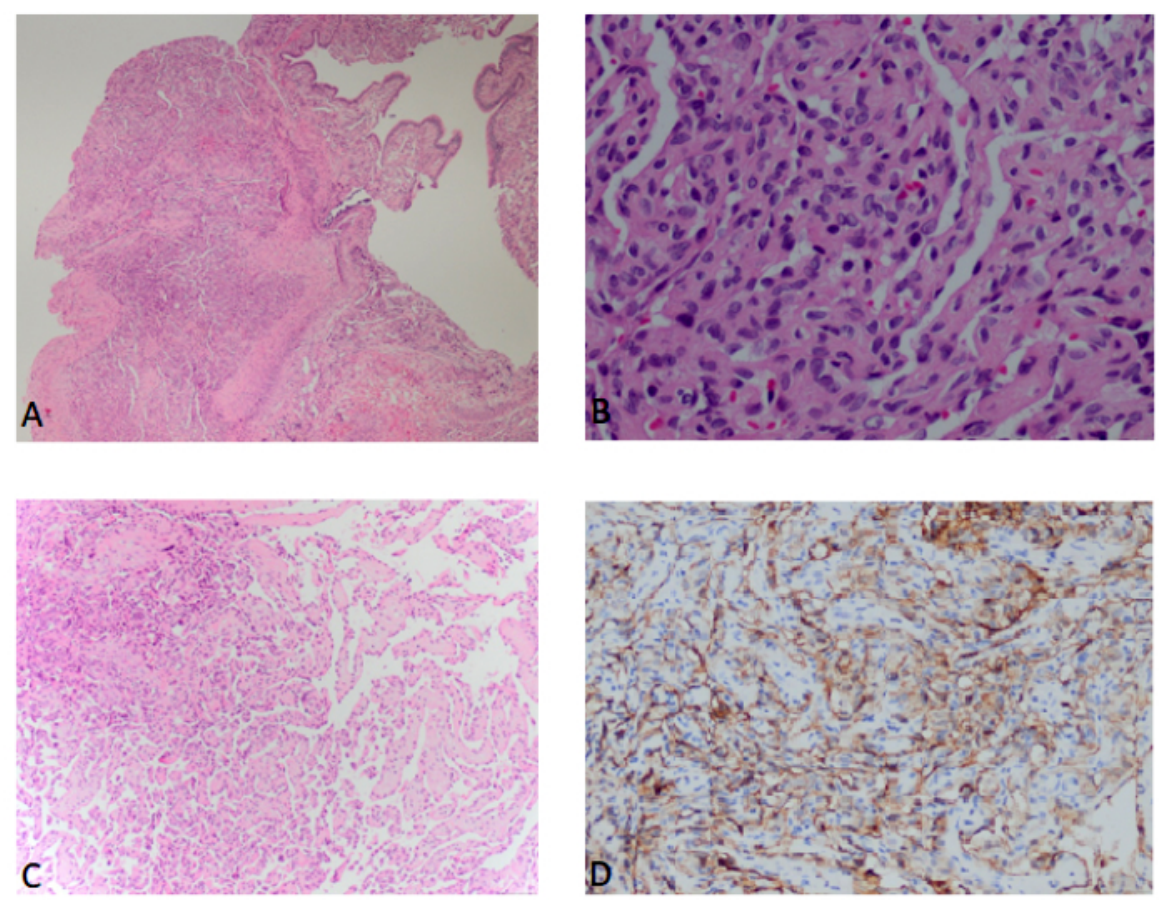

(A) Se observa el tumor debajo del epitelio respiratorio, contiene hendiduras vasculares (tinción con hematoxilina y eosina, x4). (B) Proliferación de células endoteliales con vacuolas intracitoplasmáticas acompañadas de extravasación eritrocitaria (tinción con hematoxilina y eosina, $\mathrm{x} 40$ ).

(C) Áreas de hiperplasia endotelial papilar (tinción con hematoxilina y eosina, x10).

(D) En el examen inmunohistoquímico, las células tumorales fueron positivas para CD31. 
ponderadas en $\mathrm{T} 1$ posgadolinio.

Al paciente se le realizó un seguimiento conservador porque se consideró que la cirugía era riesgosa, y se continuó el tratamiento con propranolol por vía oral. Sin embargo, la obstrucción nasal no mejoró, y el paciente comenzó a tener hemorragias nasales frecuentes. Se discontinuó el propranolol cuando el paciente tenía 8 meses de edad y se optó por la extirpación quirúrgica del tumor de manera endoscópica bajo anestesia general. El tumor era frágil y vascular y ocupaba la región etmoidal. Se exploraron la base anterior del cráneo y la órbita; la lámina papirácea era anormal. Se extirpó el tumor del área de la periórbita y de la base del cráneo con abordaje endoscópico. Se extirpó en cuatro fragmentos: el más grande medía $3 \mathrm{~cm}$ x 2,5 cm x 1,3 cm; a nivel macroscópico, la muestra era marrón e irregular. En el examen histopatológico, se observó un hemangioma fusocelular, resultado similar al de la biopsia inicial.

En la RM realizada tres meses después de la cirugía, se notó una lesión residual de $1,5 \mathrm{~cm} x$ $1,7 \mathrm{~cm} \times 1 \mathrm{~cm}$ en el seno frontal izquierdo y en los senos frontoetmoidales, con las mismas características mencionadas anteriormente (Figura 2). A los seis meses de seguimiento, se observó una regresión mínima con lesiones residuales. Durante el seguimiento, el paciente no presentó otros síntomas y, en los estudios de diagnóstico por imagen realizados 30 meses después de la cirugía, se observó que el tumor residual había desaparecido.

La familia del paciente otorgó el consentimiento informado.

\section{DISCUSIÓN}

El hemangioma fusocelular es una lesión benigna poco frecuente, que afecta principalmente las extremidades y podría presentarse como un tumor solitario o multifocal, doloroso o indoloro. ${ }^{2,4}$ En general, el hemangioma fusocelular se presenta como un nódulo en las extremidades. ${ }^{2}$ Si bien ya se informaron 11 casos de hemangioma fusocelular en la región de cabeza y cuello, ${ }^{3}$ nuestro caso es de interés e inusual debido a que, hasta donde sabemos, es el primer paciente con compromiso de los senos paranasales. Si bien

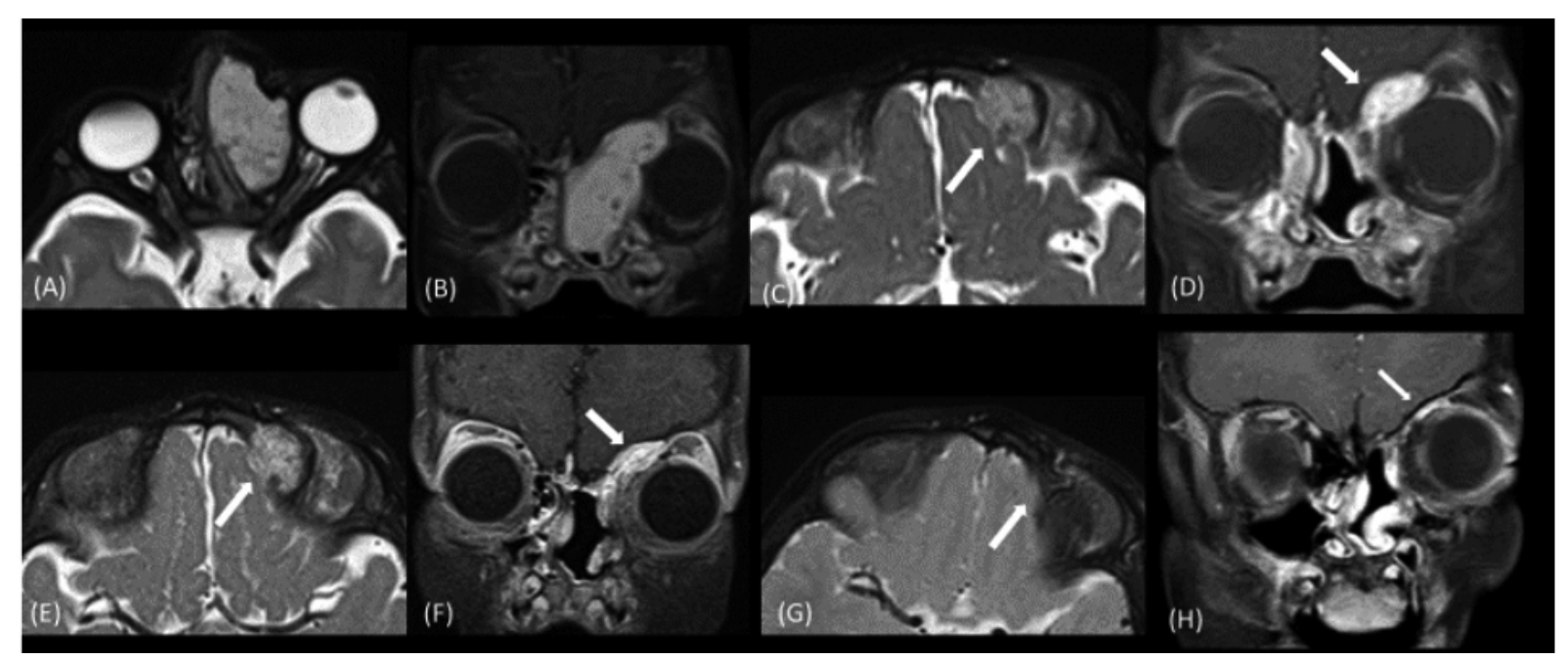

La imagen transversal ponderada en T2 con supresión grasa muestra un tumor hiperintenso con adelgazamiento festoneado de la lámina papirácea que se extiende hacia la grasa orbitaria extracónica (A). La imagen de plano frontal ponderada en T1 con supresión grasa posterior a la administración del contraste muestra realce del tumor intenso, aunque heterogéneo (B). La imagen transversal ponderada en T2 (C) y la imagen de plano frontal ponderada en T1 con supresión grasa posterior a la administración del contraste (D), tres meses después de la cirugía, muestran un tumor residual en los senos frontoetmoidales (flechas). El tumor residual muestra una disminución gradual del tamaño seis meses después de la cirugía (flechas), como se observa en la imagen transversal ponderada en T2 (E) y en la imagen de plano frontal ponderada en T1 con supresión grasa posterior a la administración del contraste (F). En la RM más reciente como parte del seguimiento, 30 meses después de la cirugía, la imagen transversal ponderada en T2 (G) y la imagen de plano frontal ponderada en T1 con supresión grasa posterior a la administración del contraste (H) no muestran señales de enfermedad activa (flechas). 
la mayoría de los casos informados no tenían síntomas, nuestro paciente tenía tumefacción del párpado izquierdo, obstrucción nasal y hemorragias nasales. El hemangioma fusocelular puede observarse a cualquier edad; ${ }^{2}$ en nuestro paciente, puede considerarse congénito dado que la tumefacción del párpado izquierdo se observó desde el nacimiento y la obstrucción nasal, desde las 2 semanas de vida.

Si bien la mayoría de las lesiones de hemangioma fusocelular miden menos de $2 \mathrm{~cm},{ }^{5}$ en nuestro caso, fue notorio que el material extirpado era mucho más grande.

En el examen histopatológico del hemangioma fusocelular, se observan espacios vasculares cavernosos que podrían contener un trombo y que están revestidos por células endoteliales y áreas sólidas de células fusiformes. Las áreas de células fusiformes también incluyen células endoteliales epitelioides con vacuolas citoplasmáticas. En general, la atipia nuclear es leve en el hemangioma fusocelular y, raramente, muestra actividad mitótica. ${ }^{6}$ Sin embargo, este caso de hemangioma fusocelular también tenía áreas de hiperplasia endotelial papilar, pocas veces informada en la bibliografía. ${ }^{5,78}$ En el examen inmunohistoquímico del hemangioma fusocelular, los vasos capilares y cavernosos son positivos para CD31, y el área de células fusiformes es positiva para la actina de músculo liso. ${ }^{9}$ Si bien se creía que la lesión se originaba en los vasos sanguíneos, un estudio reciente indicó que las células endoteliales del hemangioma fusocelular son positivas para PROX-1 (que se expresa en la proliferación linfática) y sugirió que el hemangioma fusocelular es una malformación linfática. ${ }^{10}$ Recientemente, se describieron mutaciones somáticas en mosaico en la enzima isocitrato deshidrogenasa IDH1 e IDH2 en el hemangioma fusocelular, aunque no en otras lesiones vasculares. Kurek y cols., demostraron que el $71 \%$ de los casos de hemangioma fusocelular tenían una mutación en IDH1/IDH2. ${ }^{11}$ Otro estudio reveló que 16/17 casos de hemangioma fusocelular tenían una mutación en IDH1/IDH2, y estas mutaciones no se encontraron en otras anomalías vasculares con malformación linfática. Por lo tanto, se concluyó que esta mutación es sumamente específica del hemangioma fusocelular y puede usarse a modo de diagnóstico. ${ }^{12}$

Varias lesiones del hemangioma fusocelular podrían estar asociadas con el síndrome de Maffucci, el síndrome de Klippel-Trenaunay, el linfedema congénito y las várices. ${ }^{2,7}$ No se observó ninguno de estos síndromes en nuestro paciente.

Si bien el hemangioma fusocelular es una lesión benigna, se informaron recidivas en hasta el $58 \%$ de los casos. ${ }^{2}$ Más de la mitad de las lesiones son parcial o totalmente intravasculares, y las recidivas locales se producen en los vasos de la región donde se encuentra la lesión primaria. El pronóstico general es excelente con la extirpación quirúrgica total. No se informaron metástasis ni defunciones a causa del hemangioma fusocelular. ${ }^{2}$ Además, se reportaron casos de regresión espontánea. ${ }^{7}$ A nuestro paciente se le realizó una cirugía transnasal endoscópica debido a las ventajas que ofrecen su baja morbilidad, el hecho de que no requiere incisión y la visualización detallada. Sin embargo, no fue posible la extirpación total debido a la ubicación del tumor. Afortunadamente, el tumor residual de nuestro paciente presentó regresión espontánea y desapareció. Además, también se informó el caso de una niña de 10 años con nódulos de hemangioma fusocelular en el tobillo y el pie tratados satisfactoriamente con escleroterapia. ${ }^{13}$ No se recomienda la radioterapia, ya que se informó un caso con transformación maligna y metástasis ganglionar después de la radioterapia. ${ }^{1}$ Por lo tanto, se planificó el seguimiento riguroso del paciente para detectar cualquier recidiva tras la regresión espontánea.

El hemangioma fusocelular no es un tumor frecuente en la región de cabeza y cuello, y los síntomas podrían no ser indicativos del diagnóstico, como en el caso de nuestro paciente. Dado que esta entidad es poco conocida y tiene el potencial clínico de confundirse en el diagnóstico con hemangiomas u otras lesiones vasculares, es muy relevante realizar el diagnóstico histopatológico para planificar el tratamiento. De este modo, la sensibilización sobre este diagnóstico podría aumentar los casos informados.

\section{REFERENCIAS}

1. WeissSW,EnzingerFM.Spindlecellhemangioendothelioma. A low-grade angiosarcoma resembling a cavernous hemangioma and Kaposi's sarcoma. Am J Surg Pathol.1986; 10(8):521-30.

2. Perkins P,Weiss SW.Spindle cell hemangioendothelioma. An analysis of 78 cases with reassessment of its pathogenesis and biologic behavior. Am J Surg Pathol. 1996; 20(10):1196-204.

3. French KE, Felstead AM, Haacke N, Theaker J, et al. Spindle cell haemangioma of the tongue. J Cutan Pathol. 2016; 43(11):1025-7.

4. Hakozaki M, Tajino T, Watanabe K, Yamada H, et al. Intraosseous spindle cell hemangioma of the calcaneus: a case report and review of the literature. Ann Diagn Pathol. 
2012; 16(5):369-73.

5. Tosios KI, Gouveris I, Sklavounou A, Koutlas IG. Spindle cell hemangioma (hemangioendothelioma) of the head and neck: case report of an unusual (or underdiagnosed) tumor. Oral Surg Oral Med Oral Pathol Oral Radiol Endod. 2008; 105(2):216-21.

6. Marušić Z, Billings SD. Histopathology of Spindle Cell Vascular Tumors. Surg Pathol Clin. 2017; 10(2):345-66.

7. Fletcher CD, Beham A, Schmid C. Spindle cell haemangioendothelioma: a clinicopathological and immunohistochemical study indicative of a non-neoplastic lesion. Histopathology. 1991; 18(4):291-301.

8. Tosios K, Koutlas IG, Kapranos N, PapanicolaouSI.Spindlecell hemangioendothelioma of the oral cavity. A case report. J Oral Pathol Med. 1995; 24(8):379-82.

9. TsukamotoS, Honoki K, Shimada K, Fujii H, et al. Periosteal spindle cell hemangioma of the fibula: a case report. Skeletal Radiol. 2013; 42(8):1165-8.

10. Wang L, Gao T, Wang G. Expression of Prox1, D2-40, and WT1 in hemangioma fusocelular. J Cutan Pathol. 2014; 41(5):447-50.

11. Kurek KC, Pansuriya TC, van Ruler MA, van den Akker $\mathrm{B}$, et al. R132C IDH1 mutations are found in spindle cell hemangiomas and not in other vascular tumors or malformations. Am J Pathol. 2013; 182(5):1494-500.

12. Ten Broek RW, Bekers EM, de Leng WWJ, Strengman E, et al. Mutational analysis using Sanger and next generation sequencing in sporadic spindle cell hemangiomas: A study of 19 cases. Genes Chromosomes Cancer. 2017; 56(12):855-60.

13. Kramer D, Downey C, Vargas P, Castro A. Multifocal spindle cell hemangioma: Report of two cases. Indian J Dermatol Venereol Leprol. 2016; 82(1):93-5. 